\title{
Pressure and Gas Flow Distribution Inside the Filter of a Non-Filter Ventilated Lit Cigarette During Puffing *
}

\author{
by \\ Bin $\mathrm{Li}^{1}$, Xiaomeng Cui ${ }^{1}$, Lucan Zhao ${ }^{1,3}$, Le Wang ${ }^{1}$, Guoyong Xie ${ }^{2}$, and Nan Deng ${ }^{1}$ \\ Zhengzhou Tobacco Research Institute of CNTC, Zhengzhou 450001, China \\ Tobacco Hunan Industrial Co., Ltd. Changsha, 410007, China \\ Tobacco Zhejiang Industrial Co., Ltd. Hangzhou, 310000, China
}

SUMMARY

Establishing a realistic gas flow velocity distribution inside a cigarette filter during smoking is important to understand filtration mechanisms of different mainstream smoke species and the overall effect of filter designs on mainstream smoke composition. In this paper, an experimental method is described which directly measures the gas pressure field inside a cellulose acetate filter during cigarette smoking. This was demonstrated by using 3R4F research reference cigarettes smoked under a $35 \mathrm{~mL}$ puff of $6 \mathrm{~s}$ duration. In addition, filter temperature measurements were also carried out at multiple locations within the filter. Both the temperature and pressure sensing locations were selected to match the radial and longitudinal directions of the cigarette filter. The temperature and pressure measurements were then used to calculate the velocity according to Darcy's Law along the mainstream flow direction in the cigarette filter at each puff. The spatially resolved maps of temperature, pressure and flow velocity on a puff-by-puff basis provide useful insights into the dynamic filtration of smoke aerosol under the influence of the approaching burning coal and progressive accumulation of smoke particulate matter. [Beitr. Tabakforsch. Int. 27 (2017) 113-124]

KEY WORDS: Cigarette; filter; temperature; pressure; velocity distribution

\section{ZUSAMMENFASSUNG}

Die Bestimmung einer realistischen Verteilung der Gasströmungsgeschwindigkeiten in einem Zigarettenfilter während des Rauchens ist wichtig, um den Filtrationsmechanismus unterschiedlicher Hauptstromraucharten verstehen und die Gesamtwirkung von Filterdesigns auf die Zusammensetzung des Hauptstromrauchs einschätzen zu können. In der vorliegenden Arbeit wurde eine Versuchsmethode zur direkten Messung eines Gasdruckfeldes im Inneren eines Celluloseacetatfilters beim Rauchen einer Zigarette entwickelt. Dazu wurde eine 3R4F-Referenzzigarette zu Prüfzwecken verwendet, die mit einem Zugvolumen von $35 \mathrm{~mL}$ und einer Zugdauer von $6 \mathrm{~s}$ geraucht wurde. Außerdem wurden an verschiedenen Stellen im Filter Temperaturmessungen durchgeführt. Die Stellen für die Filtertemperatur- und Druckmessungen wurden jeweils entsprechend der radialen und longitudinalen Richtung des Zigarettenfilters ausgewählt. Die Temperatur- und Druckmessungen wurden anschließend verwendet, um nach dem Gesetz von Darcy bei jedem Zug die Geschwindigkeit in der Strömungsrichtung des Hauptstroms im Zigarettenfilter zu berechnen. Die räumlich hochauflösenden Abbildungen von Temperatur, Druck und Strömungsgeschwindigkeit für den einzelnen Zug liefern aufschlussreiche Erkenntnisse über die dynamische Filtration des Rauch-Aerosols unter dem Einfluss der sich nähernden brennenden Spitze und einer fortschreitenden Ansammlung von Rauchpartikeln. [Beitr. Tabakforsch. Int. 27 (2017) 113-124] 


\section{RESUME}

La cartographie réaliste de la répartition des vitesses d'écoulement des gaz à l'intérieur d'une cigarette est essentielle à la compréhension du mécanisme de filtration des différentes espèces de fumée principale ainsi que de l'effet global des modèles de filtres sur la composition de la fumée principale. Le présent article propose une méthode expérimentale établie en vue de mesurer directement le champ de pression des gaz à l'intérieur du filtre en acétate de cellulose lors de la consommation d'une cigarette. La démonstration utilise la cigarette d'essai 3R4F, fumée par bouffées de $35 \mathrm{~mL}$ durant 6 secondes. En outre, des mesures de la température du filtre sont également prélevées en de multiples points à l'intérieur du filtre. La localisation tant des points de mesure de pression que des points de mesure de température est choisie pour correspondre aux directions longitudinales et radiales du filtre de cigarette. Les relevés de pression et de température sont ensuite utilisés pour le calcul de la vélocité suivant la loi de Darcy tout au long du sens d'écoulement principal du filtre de cigarette à chaque bouffée. Les cartes à haute résolution de répartition spatiale des températures, des pressions et des vitesses d'écoulement pour chaque bouffée livrent des informations utiles concernant la filtration dynamique de l'aérosol de fumée sous l'influence de la proximité croissante du bout incandescent et de l'accumulation progressive des particules de fumée. [Beitr. Tabakforsch. Int. 27 (2017) 113-124]

\section{INTRODUCTION}

Cigarette filters play an important role in removing a portion of mainstream smoke aerosol compared to unfiltered cigarettes. In addition, they provide a functional mouthpiece and prevent tobacco particles from entering the consumer's mouth (1). The most widely used cigarette filter type consists of a single rod of cellulose acetate (CA) fibre. Other filter designs with modified geometry and incorporating granulated charcoal are also popular in certain parts of the world. The choice of the CA fibre (cross-sectional shape and optical diameter of a single fibre filament) depends largely on the target firmness (resistance to moisture and temperature) and pressure drop (the effort applied by a consumer to draw an acceptable amount of aerosol) of the filter. The firmness of the filter is achieved by applying a small amount of plasticiser (usually triacetin or 1,2,3-triacetoxypropane, for up to $6 \%$ by weight) during the filter manufacturing process.

Because smoke removal efficiency and filter pressure drop are two important and interlinked parameters in modern cigarette design, extensive research has been conducted to understand the mechanisms for both general aerosol filtration and selective chemical constituent interaction (1). It is known that aerosol behaviour at molecular levels influences particle/aerosol interception and filtration (2). Studies by KEITH and co-workers reveal that in filtered cigarettes, smoke aerosol particles are retained by cellulose acetate fibre via three mechanisms: interception, inertial impaction and diffusional deposition (3-6). Relatively speaking, impaction is enhanced by high flow rates (7) and larger particles, whereas diffusional deposition evokes the opposite. Interception on the other hand is relatively independent of flow rate. It is possible to predict the overall filtration behaviour of $\mathrm{CA}$ filter by modelling the relative contributions from these mechanisms during cigarette smoking (8).

Cellulose acetate filters do not just remove aerosol particles by the physical mechanisms mentioned above. A significant degree of selective filtration (i.e., certain chemical classes of aerosol components are retained better than the average aerosol filtration efficiency) has also been noted, especially for the semi-volatile fraction of the cigarette smoke components such as phenolic compounds $(9,10)$. This chemistryrelated filtration is thought to occur due to a portion of the smoke compounds present in the vapour phase. As the smoke passes through the filter, different degrees of chemical affinity towards the plasticiser and/or filter material by different classes of compounds cause variation in their retention. To this end, incorporating other adsorptive materials such as granular charcoal or amine-functionalised resin beads provides further opportunities to chemically interact with volatile and semi-volatile organic compounds such as aldehydes and hydrogen cyanide $(11,12)$.

Modern commercial cigarettes have ventilation holes through the wrapping paper surrounding the CA filter in order to dilute the mainstream smoke under puffing $(1,13$, 14). Compared to unventilated cigarettes, the chemical composition of the mainstream smoke is also affected by both, changes in the burning tip and in the smoke formation processes $(15,16)$. The position of the ventilation holes and their distribution may also have a secondary influence on the filtration behaviour of the filter. Performance and efficiency of cigarette filters are often evaluated using standard machine smoking parameters (or regimes) based on comparing mainstream smoke yields of cigarettes equipped with these filter in laboratory conditions (13). These standard smoking protocols do not represent how a cigarette might be used by a smoker (17). Humans smoke a cigarette in a variety of different ways, only specially designed smoking machines can replicate the varied range of puffing parameters based on recorded human puffing topography. Irrespective of human or machine smoking, cigarette filters and their design features play an important role in consumer's sensory perception and the laboratory testing of cigarettes (18-20).

The effects of cigarette puffing parameters on filtration are mainly controlled by the smoke flow rate with a given filter design and are fundamentally governed by aerosol dynamics. Another aspect of the filter behaviour is that all the physical and chemical processes of smoke filtration occur dynamically, with each puff taken the filter is modified by the aerosol deposited within. The length of the tobacco rod is consumed puff-by-puff, altering the chemical composition and physical properties of the aerosol particles at the source $(13,15)$. The residence time offered by a typical cigarette filter of $27 \mathrm{~mm}$ length varies from a few to few tens of milliseconds; fresh mainstream smoke can "age" rapidly both physically (rapid decrease in particle concentration accompanied by growth in particle size and mass) and chemically (quenching of highly reactive species such a free radicals) as it passes through the filter. In addition, 
the temperature of the filter material increases gradually over time and spatially in longitudinal direction as a result of the approaching burning coal (21). These highly interlinked chemical mass and heat transfer processes in the filter imply that the filtration mechanisms should be studied in a spatially-related way. In a recent study of this kind (22), localised filtration of a number of volatile, semivolatile and particulate phase smoke components (e.g., ammonia, phenol, nicotine, benzo[ $a]$ pyrene, hydrogen cyanide) within a cellulose acetate filter was quantified by analysing cut smoked filter segments - small segments of the used filter were cut using a precision laser cutter to provide averaged concentrations of filtered compounds. The results confirmed that the compounds trapped or filtered by the cellulose acetate filter display different retention patterns in the used filter, suggesting spatially variable filtration mechanisms which may be linked to the flow and accumulation of the smoke condensate on a puffby-puff basis (23). One limitation of this recent study was that it showed a final picture of the combined filtration and relied on analyses of the averaged chemical composition. In this work, we developed a pressure micro-sensor technique to measure the local pressure distribution within a cigarette filter. We combined this technique with thermocouple-based temperature measurements and calculated the gas flow patterns within the filter during cigarette smoking in situ. We believe these data will be useful to further understand the factors influencing the chemical and physical interactions between smoke aerosol particles and the cellulose acetate filter.

\section{EXPERIMENTAL TECHNIQUES}

\subsection{Pressure sensor module}

A pressure micro-sensor module (Figure 1) was designed to measure the pressure within a cigarette filter. The module consists of six quartz pressure sensors, each has $0.35 \mathrm{~mm}$ outer diameter and $0.2 \mathrm{~mm}$ inner diameter (it was assumed here that the effect on the measurement of pressure with the fine sensors could be ignored). They were spaced $3 \mathrm{~mm}$ apart and between the six pressure sensors there was a single $0.254-\mathrm{mm}$ diameter thermocouple (shown as dashed line in Figure 1). The temperature reading from this thermocouple was used to provide an independent temperature calibration to compare the temperature and pressure measurements. The six pressure sensors were connected to a digital pressure transducer (Anhui Institute of Optics and Fine Mechanics, Chinese Academy of Sciences, Hefei, China), with a range of -2048 to $+2048 \mathrm{~Pa}$ at $10 \mathrm{~Hz}$ of recording rate. Its full range accuracy was within $5 \%$.

To conduct a pressure measurement, a test cigarette was first fixed to its holder so that its position could be read by an $\mathrm{x}-\mathrm{y}$ digital micrometer (Figure 1). A precision needle ( $0.5 \mathrm{~mm}$ diameter) was pierced through the filter wrapper at a pre-defined location to make an insertion hole to the required depth. This was repeated for all the pressure sensors and once for the thermocouple. The pressure sensor module held the sensor array together for protection and for positioning, it was driven by a micro motor (precision of
$0.1 \mathrm{~mm}$ ) and controlled by software. The first sensor on the left was inserted at $57 \mathrm{~mm}$ from the lighting end of the cigarette, i.e., the left edge of the cigarette filter (which is $27 \mathrm{~mm}$ long, see Table 1 and Figure 1). The width of the sensor module covered the filter length of $15 \mathrm{~mm}$, leaving $12 \mathrm{~mm}$ for the cigarette to be inserted into a smoking machine on the right (Figure 1). Nine radial insertion holes spaced $0.97 \mathrm{~mm}$ apart were made in filter rod. Because of the vertical axial symmetry of the filter rod (cigarette rod horizontally positioned), only half of the cross-section was measured. Responses from all the sensors were tested to ensure that no blocking occurred during insertion. Any gaps between the wrapping paper and the sensors were sealed with a small amount of paper glue.

Table 1. Test cigarette (3R4F) and its main physical parameters.

\begin{tabular}{lc}
\hline Cigarette length $(\mathrm{mm})$ & 84 \\
Tobacco rod length $(\mathrm{mm})$ & 57 \\
Circumference (mm) & 24.8 \\
Unlit draw resistance (mm /WG) & 128 \\
Cigarette weight (g) & 1.06 \\
Tobacco weight (g) & 0.775 \\
Tobacco moisture level (\%) & 13.0 \\
Cigarette paper air permeability (CORESTA unit) * & 24 \\
Cigarette paper burn additive (citrate) (wt\%) & 0.60 \\
As-received filter ventilation level (\%) & 30 \\
\end{tabular}

* CORESTA unit is defined as the air flow $\left(\mathrm{cm}^{3} \mathrm{~min}^{-1}\right)$ passing through $1 \mathrm{~cm}^{2}$ of test material at an applied pressure of $1.00 \mathrm{kPa}$.

\subsection{Temperature sensor module}

The thermocouple module used in this work for temperature measurements was the same as the one described before $(24,25)$. Briefly, up to eight K-type thermocouples $(0.254 \mathrm{~mm}$ outer diameter) were loaded into a digital $\mathrm{x}-\mathrm{y}$ stage for positioning and insertion (accuracy within $\pm 0.1 \mathrm{~mm}$ ). A digital-to-analogue converter (Model OM-87 DAQ-USB-2401, OMEGA, Stamford, Connecticut, USA) read the temperature responses at $10 \mathrm{~Hz}$ and stored the data. The insertion of the thermocouples followed a similar procedure as described above for the pressure sensors. In axial direction, eight insertions spaced $2 \mathrm{~mm}$ apart were made from 58 to $72 \mathrm{~mm}$ length (defined from the lighting end) (see Figure 1). In radial direction, five insertions spaced $0.97 \mathrm{~mm}$ apart, from the periphery to centre of filter were measured, and the data of $9 \cdot 8$ locations had been acquired due to rotational symmetry of the filter rod in Figure 1. All of the results presented in the work were averaged over four replicates (25). All the data treatment was carried out in MATLAB (26). 

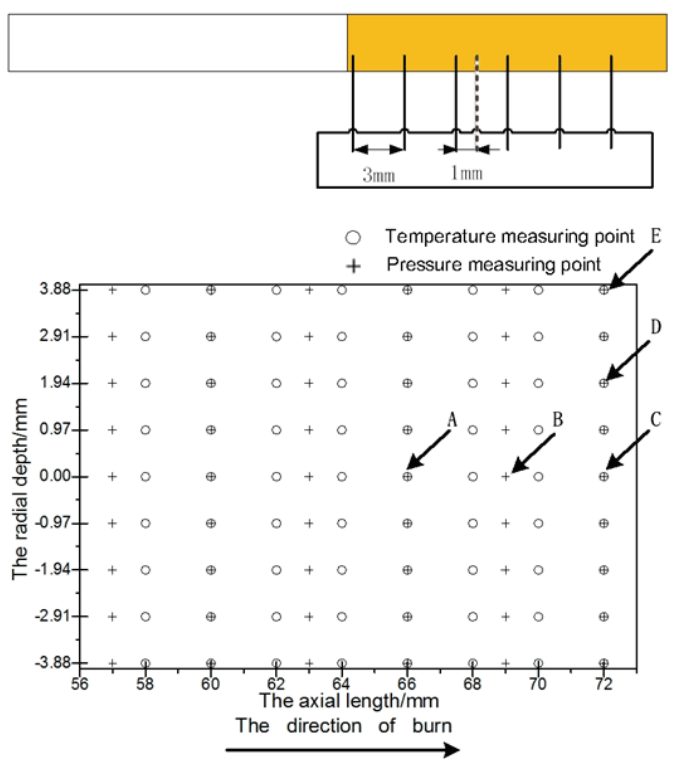
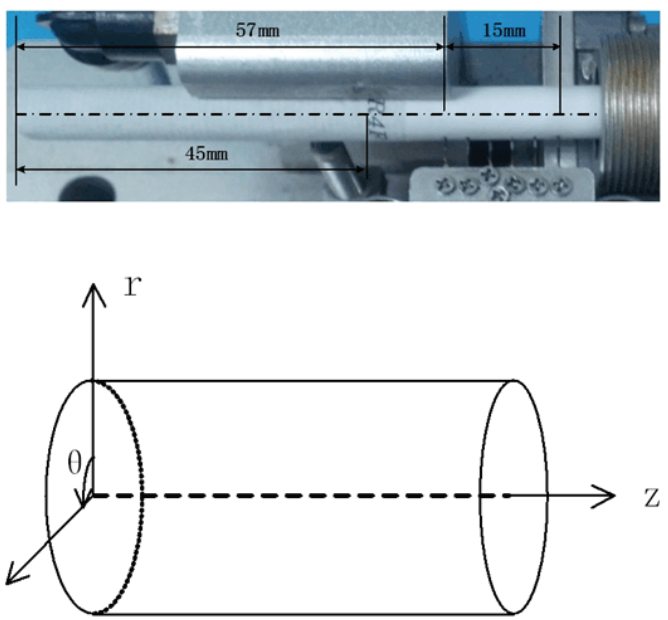

Figure 1. Schematic illustration of a test cigarette and the insertion of the pressure sensor module. Five locations for both the temperature and pressure sensor are labelled A-E.

\subsection{Gas flow velocity calculation}

With temperature and pressure measurement, it was possible to calculate the local gas flow velocity inside the filter $(27,28)$. For this purpose, the gas flow direction inside the filter was assumed to be perpendicular to the isobaric line with a tendency towards lower pressure. Quantitatively, the volumetric flow rate $\left(Q, \mathrm{~cm}^{3} \mathrm{~s}^{-1}\right)$ and pressure differential $(\triangle P, \mathrm{~Pa})$ across a given length of the filter $(L, \mathrm{~cm})$ is further assumed to obey Darcy's Law [Equation 2.1].

$$
Q=-\frac{1}{\varepsilon} A \frac{\Delta P}{L}
$$

where $A$ is the area through which the gas flows $\left(\mathrm{cm}^{2}\right), \varepsilon$ is the impedance of the filter rod at the ambient temperature $\left(\mathrm{Pa} \cdot \mathrm{s} \cdot \mathrm{cm}^{-2}\right)$ and independent of the flow direction.

The impedance of a porous filter medium to a gas flow ( $u$, $\left.\mathrm{cm} \cdot \mathrm{s}^{-1}\right)$ is directly proportional to the viscosity $(\mu, \mathrm{Pa} \cdot \mathrm{s})$ of the gas flowing through the filter, and the proportionality factor is termed permeability $k$ [Equation 2.2], its unit is Darcy or millidarcy $(\mathrm{mD})$ which is a measure of the ability of a porous medium, i.e., a CA filter rod, to transmit a fluid, such an aerosol stream.

$$
\begin{gathered}
u=-\frac{k}{\mu} \nabla P \\
Q=u A \\
\frac{1}{\varepsilon}=\frac{K}{\mu}
\end{gathered}
$$

It is further assumed that the structure of the filter does not change significantly with temperature, hence $\mathcal{E}$ is a function of $\mu$ only [Equation 2.4]. For a horizontally positioned filter, the flow may be assumed to be rotationally symmetrical, hence for a given cross-section of the filter, the component (particularly in z-direction) of gas flow velocity vector is represented by $u_{z}\left(\mathrm{~cm}^{-1}\right)$ [Equation 2.5] at temperature $T$ $(\mathrm{K})$.

$$
u_{z}=-\frac{k}{\mu} \frac{\partial P}{\partial z}
$$

At any location within a cross-section, the velocity can be further described by [Equations 2.6 and 2.7]

$$
\begin{gathered}
u_{r}=-\frac{k}{\mu} \frac{\partial P}{\partial r} \\
u_{\theta}=-\frac{1}{r} \frac{k}{\mu} \frac{\partial P}{\partial \theta}=0
\end{gathered}
$$

For a given gas, its viscosity $(\mu)$ is an inherent property, which increases significantly with temperature and less so with pressure. When $\mathrm{T}<2000 \mathrm{~K}$, the viscosity of a gas can be calculated by the Sutherland Law [Equation 2.8]:

$$
\mu=\mu_{0}\left(\frac{T}{T_{0}}\right)^{\frac{3}{2}}\left(\frac{T+B}{T_{0}+B}\right)
$$

where $T_{0}$ and $\mu_{0}$ are reference temperature and corresponding viscosity, e.g., at an ambient condition, $T_{0}=395 \mathrm{~K}$, $\left.\mu_{0}=1.818 \cdot 10^{-4} \mathrm{~Pa} \cdot \mathrm{s}\right) . B$ is a constant depending on the variety of gases within the mixture: $B=110.4 \mathrm{~K}$ (29) for air. For a burning cigarette, the temperature $(T)$ field during a puff has been previously determined (21); with the pressure field determined experimentally from this study, the gas flow velocity field can thus be calculated. 


\subsection{Puff parameter}

In this study, a puff of $6 \mathrm{~s}$ duration was used instead of an ISO standard 2-s puff duration for taking a $35-\mathrm{mL}$ puff volume (30). This was to counter the effect of inertial flow within the porous tobacco and filter rod and to allow pressure, temperature and flow velocity to be more completely captured and represented within the duration of the puff. This inertial effect has a significant effect on the pressure measurement at puffs of $2 \mathrm{~s}$ duration, as illustrated in Figure 2. Even after the end of the 2-s puff, the pressure sensed by the pressure sensor was below the ambient air pressure and it continued for at least another $2 \mathrm{~s}$ and represented about $16.93 \%$ of the total area under the pressure $v s$. time curve in Figure $2 \mathrm{~B}$ which was taken at a time after the $2 \mathrm{~s}$ puff had already ended $(31,32)$. This tailing effect was much reduced when the $35-\mathrm{mL}$ puff was taken over a 6-s duration (Figure 2D). Although this was a non-standard puff parameter, it was considered a useful treatment to establish a starting condition, from which further modelling may allow the extents of inertial flow on pressure and velocity to be mapped.

\subsection{Experimental cigarette}

The test cigarettes used in this study were 3R4F Kentucky research reference cigarette (33), their typical dimensions and other parameters are given in Table 1. Prior to the experiments, as-received cigarettes were conditioned at
$22{ }^{\circ} \mathrm{C}$ and $60 \%$ relative humidity for at least $48 \mathrm{~h}$, they were then weight-selected (within the average weight of 100 cigarettes $\pm 5 \mathrm{mg}$ ) and pressure drop selected (within the average pressure drop of 100 cigarettes $\pm 49 \mathrm{~Pa}$ ) to minimize product variability. Around 30 cigarettes were selected following this procedure. For the purpose of this study, the filter ventilation holes were blocked with a tape.

\section{RESULTS}

\subsection{Filter gas-phase temperature distribution}

When 3R4F cigarettes were smoked under the specified puffing parameters $(35 \mathrm{~mL}$ puff volume, $6 \mathrm{~s}$ puff duration, one puff every $60 \mathrm{~s}$ ), temperature responses from five locations are shown in Figure 3 together with the 6-s puff profile. In total six puffs were taken. As Figure 3 a shows, the first three puffs only caused a short temperature increase at all three locations. From the fourth puff onwards, the filter started to show a notable temperature increase at the three locations and from fifth puff, position A reached a slightly higher temperature than the other two locations. Figure $3 \mathrm{~b}$ shows that the temperature increase coincided with the 6-s puff flow and before the puff ended the temperature started to decrease. The three locations reached significantly different temperatures as a result of the sixth puff, with the maximum temperature of position A approaching $60^{\circ} \mathrm{C}$.
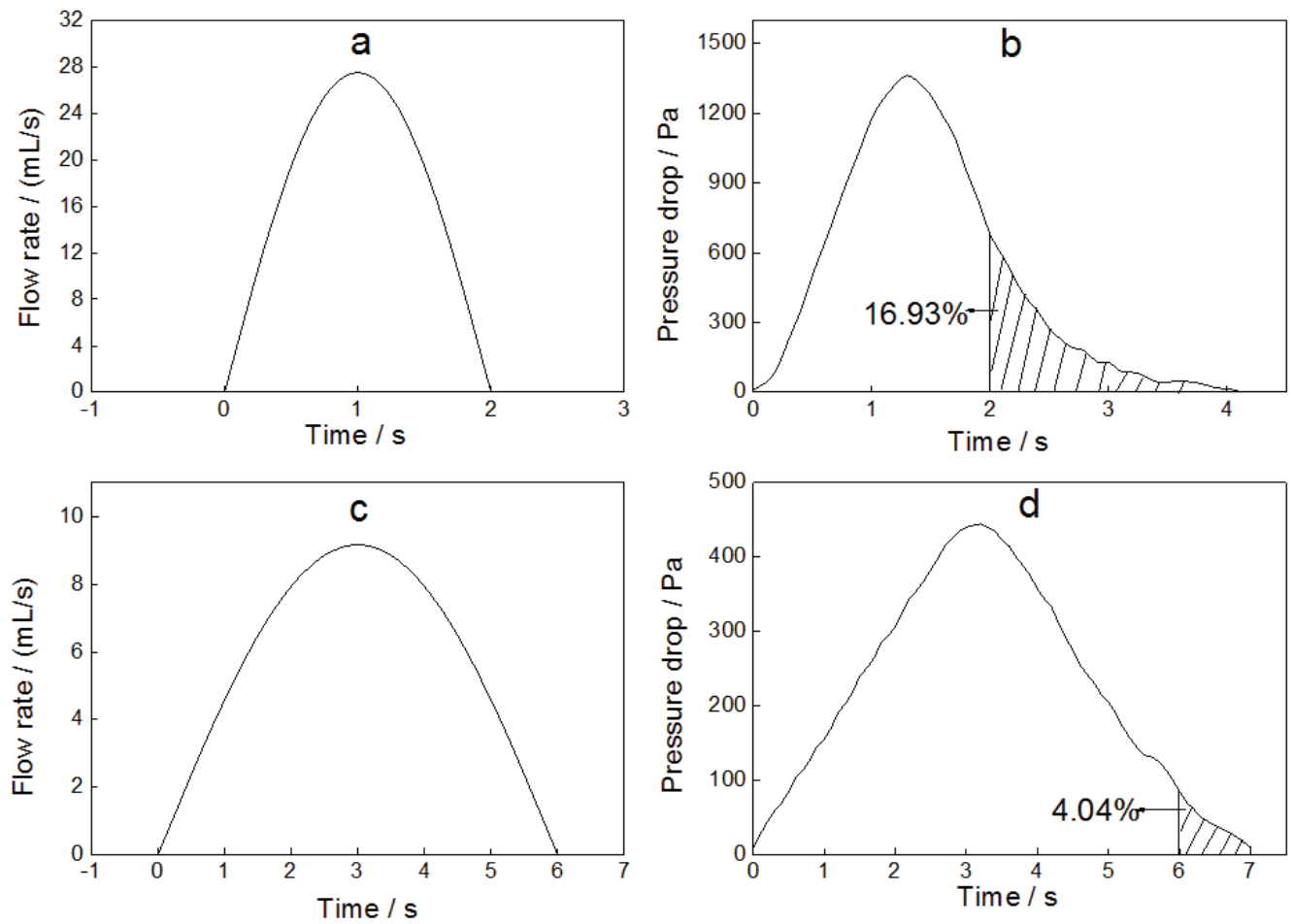

Figure 2. The volumetric flow of an ISO puff (a) and a 6-s 35-mL bell-shaped puff (c); and the corresponding pressure response inside a 3R4F cigarette filter ( $b$ and $d$ respectively). 
For the three locations in radial direction $(C, D, E)$, similar trends were seen as a function of the puff number (Figure 3c). Position $\mathrm{C}$ reached a late but higher temperature increase than the other two locations. Using the temperature measurement shown in Figure 4, the temperature distribution over a cross-section was reconstructed to illustrate the dynamic heating of the filter as the puffing cigarette tip approached the filter end (Figure 4). An appreciable temperature rise was visible only for the fifth and sixth puff across the larger part of the inner filter space (Figure 4). Furthermore, the highest temperature regions were not only located in the central region of the filter rod as the temperature also increased around the half of the filter radius.

\subsection{Pressure distribution in the filter}

Pressure measurements at the five selected locations are presented in Figure 5. In Figures 5a and 5c, it can be seen that each puff induced a sharp pressure response for approximately the duration of the puff, and there was a gently decreasing trend as puff number increased, while there was a higher-pressure response in the sixth puff. This may have been be caused by smoke aerosol particles which were absorbed by cellulose acetate tow and rendered channels narrower $(31,34)$. Among the three axial locations ( $\mathrm{A}, \mathrm{B}$ and $\mathrm{C})$, peak pressure values increased from $\mathrm{A}$ to $\mathrm{B}$ to $\mathrm{C}$ (Figure $5 \mathrm{~b}$ ). Across the radial direction (C, D and $\mathrm{E}$ ), pressures at $\mathrm{D}$ and $\mathrm{C}$ were marginally higher than at $\mathrm{E}$ (Figure 5d). The overall shape of the pressure profile matched the puff flow profile (Figure $3 \mathrm{c}$ ) very well, and the pressure reached its maximum value approximately at $3.0 \mathrm{~s}$ after the start of the 6-s puff.

All the pressure measurements were processed and used to construct a pressure distribution map, shown in Figure 6 to provide more detailed information. In a typical porous medium such as a filter rod, Darcy's Law is satisfied while the particle Reynolds number is less than $1(\operatorname{Re}<1)$ and the pressure contour across the radius direction should be relatively flat (27), this was more closely followed, in the sense of radial depth, by the first puff (Figure 6). The pressure contour became gradually more abrupt towards the later puffs (Figure 6). In each of the pressure contours the pressure values were higher on the left side, which was likely due to the higher gas temperature. Prior to the puff being taken, the pressure field within the filter was uniform and close to ambient pressure. As the puffing flow built up, concurrent to the approaching hot burning coal, localised gas pressure variation became pronounced.
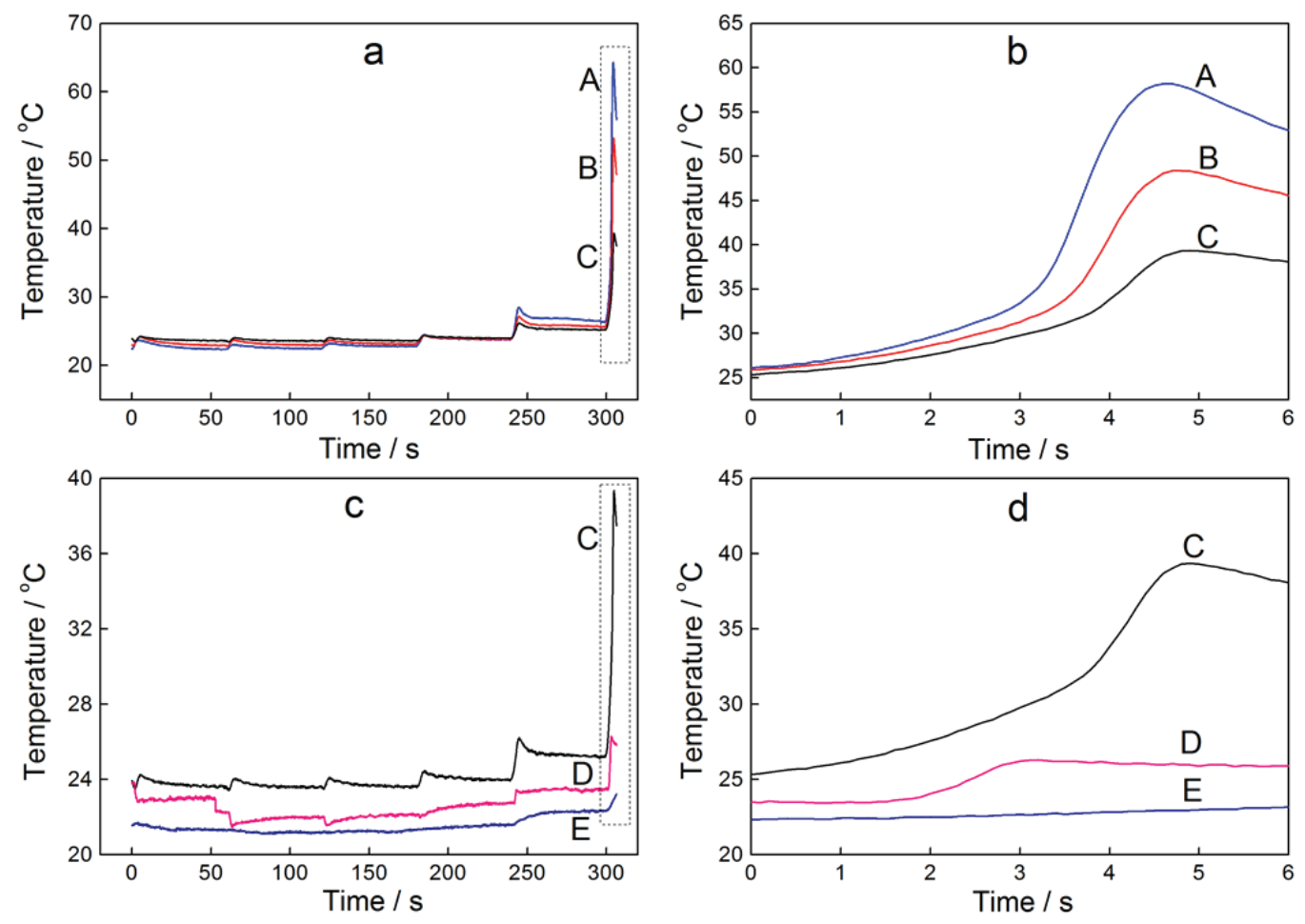

Figure 3. Temperature responses from five typical locations (cf. Figure 1) inside a 3R4F cigarette filter. 

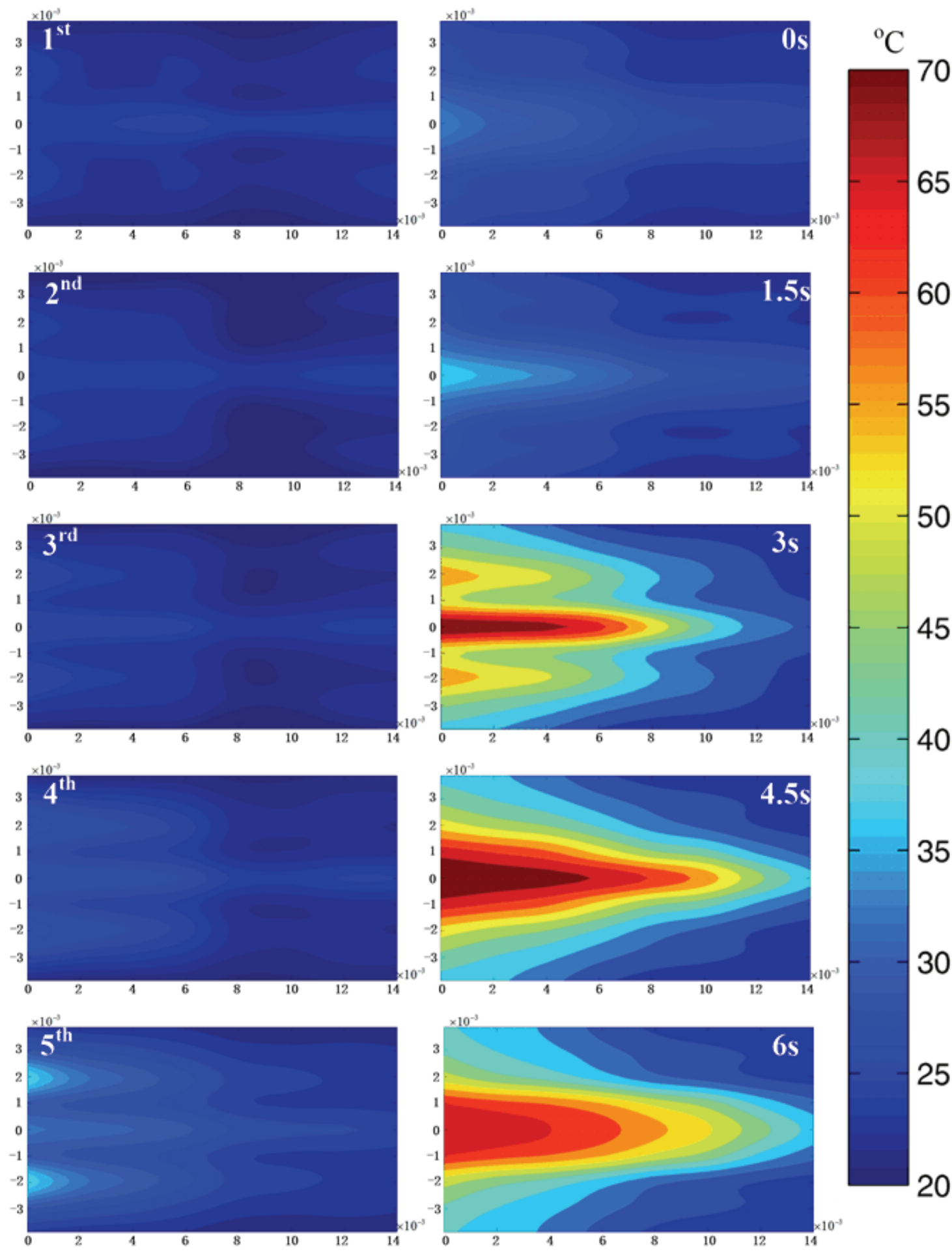

Figure 4. Constructed filter temperature $\left({ }^{\circ} \mathrm{C}\right)$ distribution maps to illustrate the temperature as a function of puff number at $3.0 \mathrm{~s}$ after the start of the 6-s puff for the first five puffs (left) and over the puff duration for the sixth puff in steps of $1.5 \mathrm{~s}$ (right). 

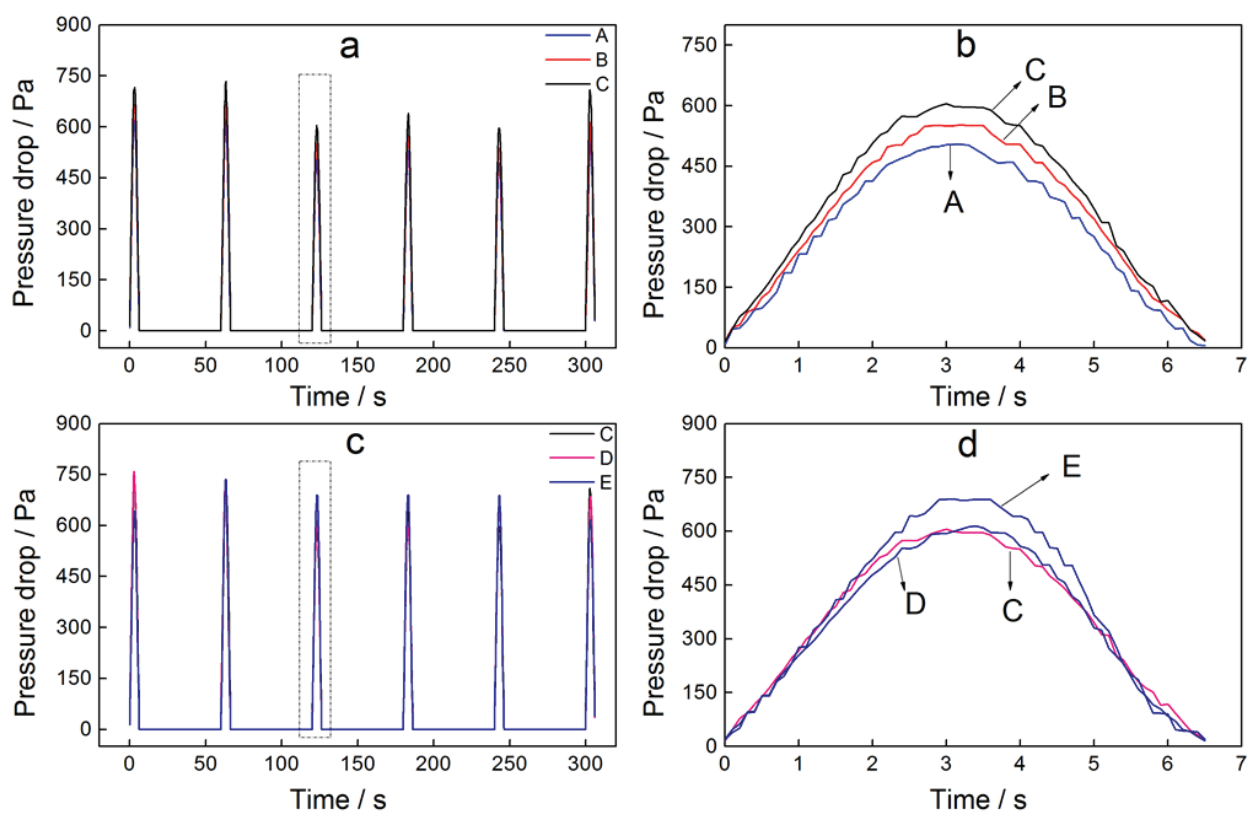

Figure 5. Pressure responses from the five labelled locations (cf. Figure 1) inside a 3R4F cigarette filter under a 6-s 35-mL bellshaped puff (left: pressure responses from the six consecutive puffs; right: puff responses from the third puff).
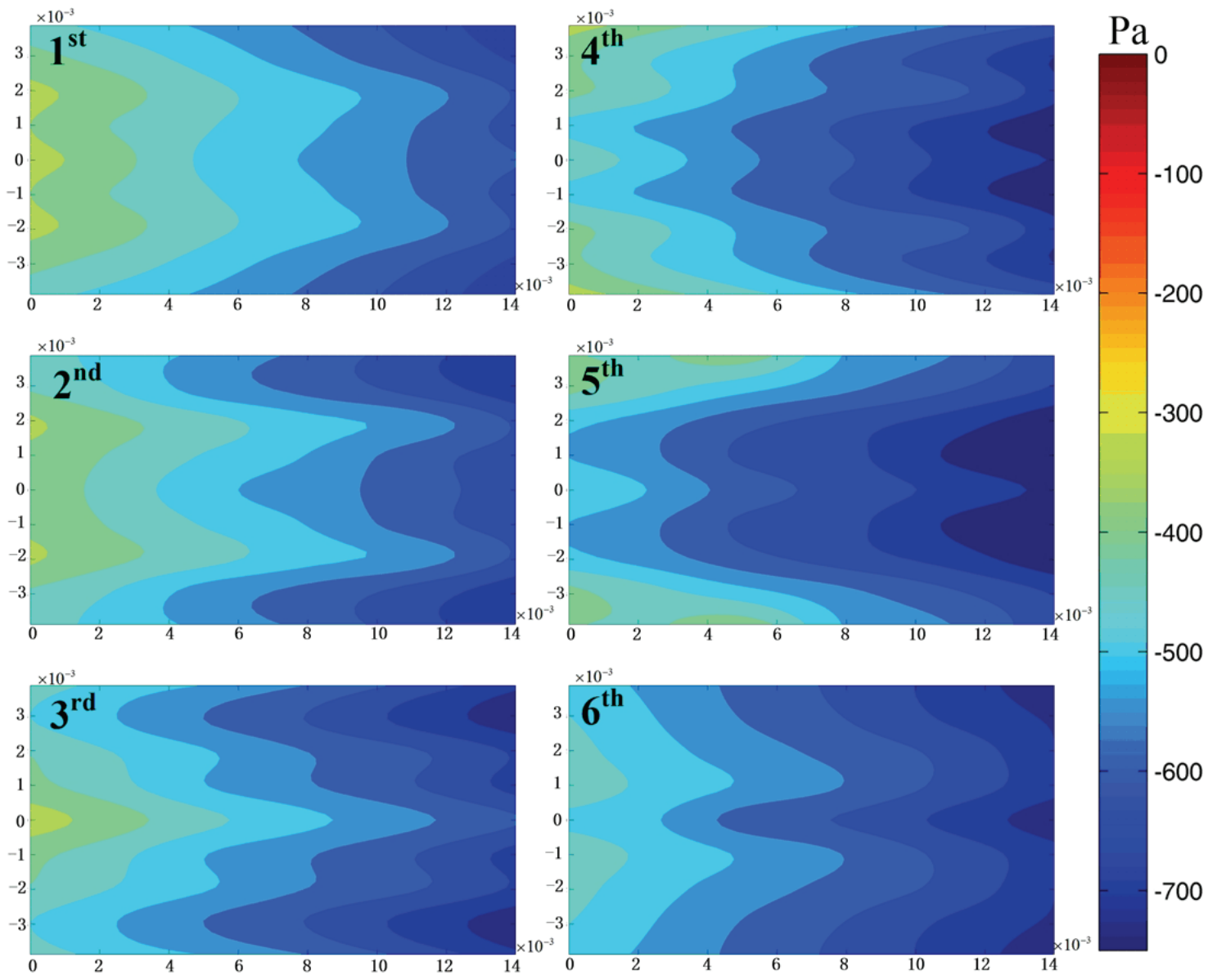

Figure 6. Constructed filter pressure ( $\mathrm{Pa}$ ) distribution maps as a function of puff number (all at $3.0 \mathrm{~s}$ after the start of the 6-s puff). 


\subsection{Gas flow velocity distribution in the filter}

When the above filter gas-phase temperature and pressure measurements (Figures 4 and 6) were combined to calculate the gas flow velocity inside the filter, a puff-by-puff resolved velocity field of the 3 -s/6-s puff for six puffs were obtained and are shown in Figure 8.

The gas velocity at the five selected locations is presented in Figure 7. It can be seen that there is less difference of gas velocity in the three axial locations (A, B and C). The velocity at location $\mathrm{C}$ is a little higher than that of $\mathrm{A}$ and $\mathrm{B}$ (Figure 7a). For the three radial locations (C, D and E), peak velocity values increased from $\mathrm{C}$ to $\mathrm{E}$ to $\mathrm{D}$ (Figure 7b). On a puff-by-puff basis (Figure 8), all six puffs appeared to have localised higher flow velocity regions around the furthest length on the right (before entering the cigarette holder).
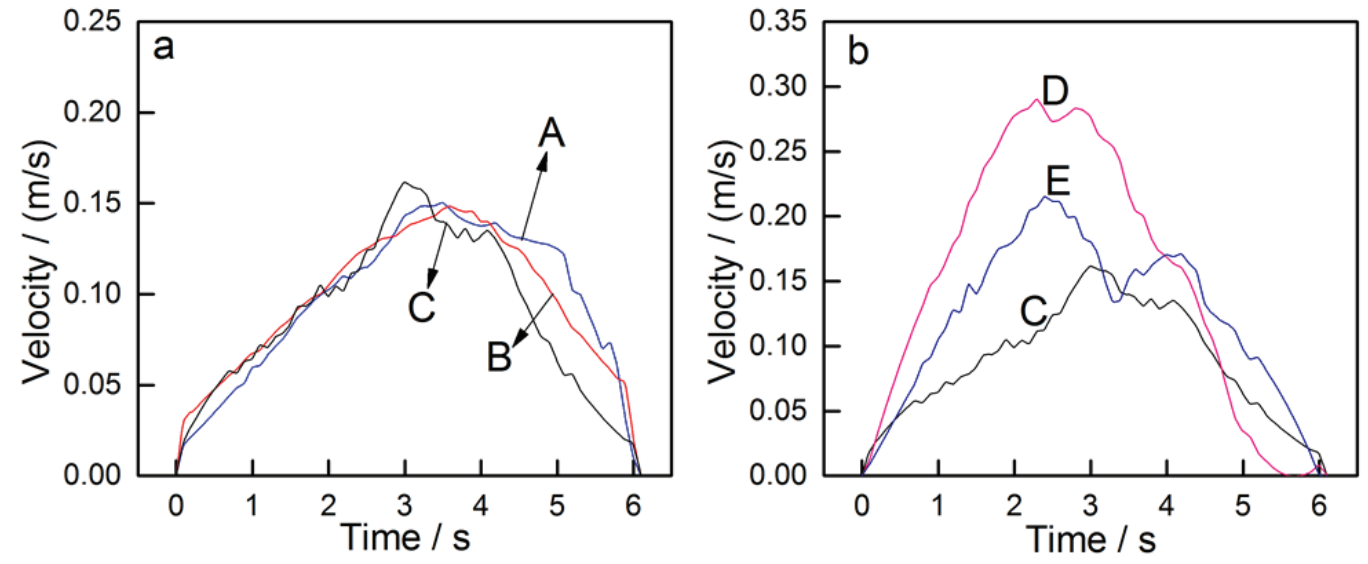

Figure 7. Gas flow velocity responses from the five labelled locations (cf. Fig. 1) inside the filter using a 6-s 35-mL bell-shaped puff.
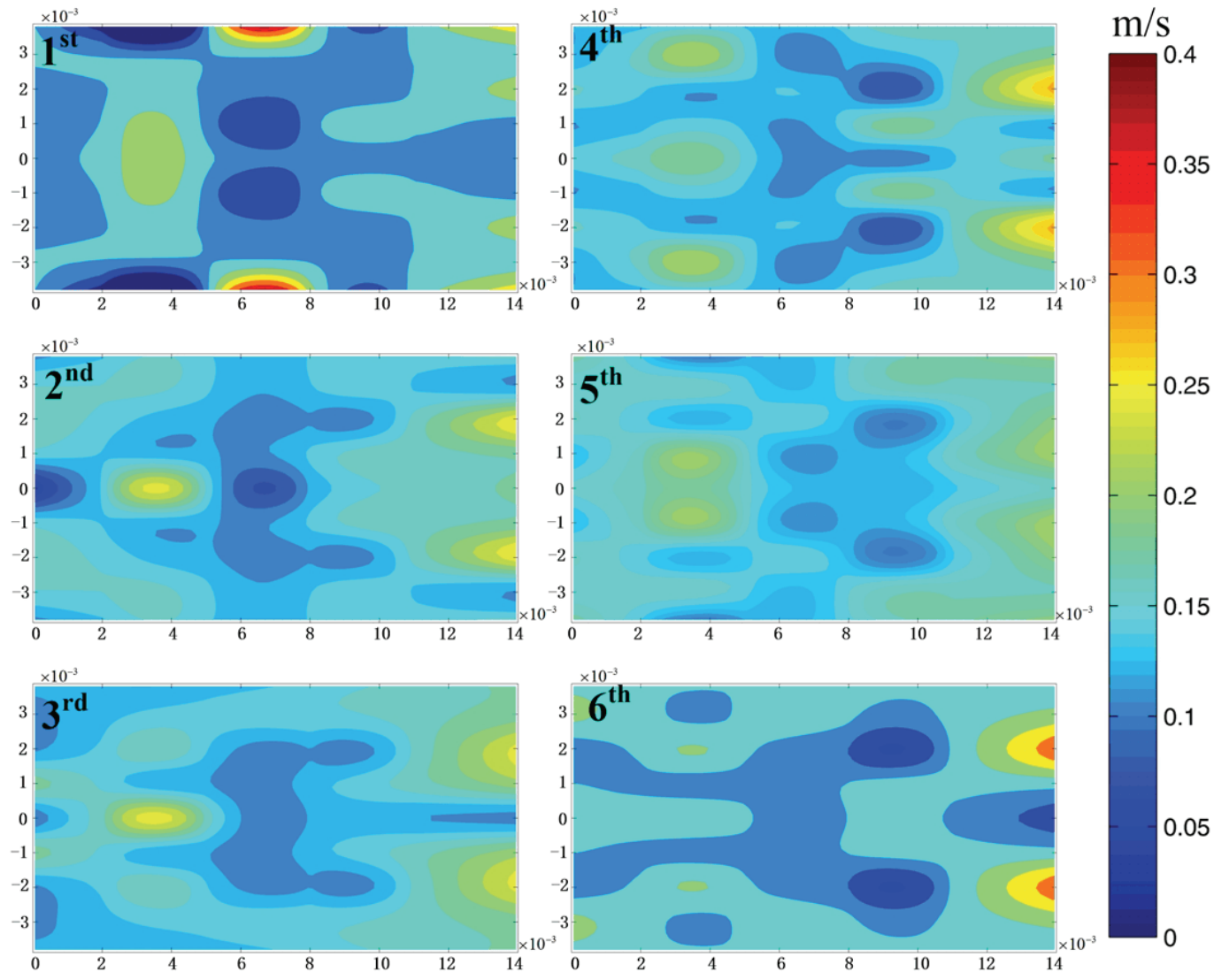

Figure 8. Constructed flow velocity $(\mathrm{m} / \mathrm{s})$ distribution maps as a function of puff number at the 3.0-s into the 6-s puff for the six puffs. 
The bulk of the central interior region experienced generally medium to low flow velocity at the 3 -s puffing flow. When viewed on a single-puff basis (Figure 7), the gradual build-up of the localised high-velocity regions on the right could be seen clearly. On the whole, the velocity distributions in Figure 8 are relatively less regionalised as compared to the temperature distribution (Figure 4) or the pressure distribution (Figure 6).

\section{DISCUSSION}

In a lit cigarette, each puff generates a certain amount of aerosol mass from the burning coal and the puffing flow drives the aerosol downstream into the filter. The filter parameters (cross-sectional shape of the tow and the tow weight, denier and the level of plasticiser) are designed to achieve a certain level of total aerosol retention when the cigarette is smoked under a defined machine-smoking protocol (1). Mechanistically, the aerosol retention by the filter occurs sequentially and on a puff-by-puff basis. As the experimental results shown in this work (Figure 6), each puff may impact the filter in its temperature. The temperature had been increasing puff-by-puff according to the heat transfer of smoke aerosol, and the temperature of smoke aerosol had been cooling while depositing partly in CA filter, thus collectively influencing the pressure distribution. Another dynamic picture explaining the filter characteristics described in this work is the fact that the tobacco rod is consumed by each puff. The burning coal is gradually approaching the filter end as a result of smouldering and puffing (15). Progressively a higher amount of aerosol mass is generated by each later puff and passed downstream to the cigarette filter. Figure 9 depicts the gas-flow patterns from the burning coal (28) in connection with the flow velocity obtained in this work: the point to note is that as the coal approaches the last or second to last puff, the gas flow is not uniform. The burning coal was at the closest distance to the filter, more exactly the paper burn line was ca. $25 \mathrm{~mm}$ away from the left edge of the filter. This undoubtedly has directly affected the aerosol flow within the tobacco rod before it reached the filter rod from one end. These factors interacted, affecting the filtration and retention of the smoke aerosol and resulted in the observed flow velocity distributions within the volume of the filter. In turn, the interaction of different classes of chemical compounds within both the particulate and vapour phase of the smoke will react differently, as has been experimentally revealed before $(4,22,23)$.

The temperature measurements obtained in this work broadly agree with previously published studies (21). When the filter temperature reaches about 60 to $70{ }^{\circ} \mathrm{C}$ it will cause softening of the cellulose acetate fibre and possible result in enhanced chemical interactions between the plasticiser and some semi-volatile compounds which otherwise would not occur to the same extent in the earlier puffs (22). Further work is ongoing to investigate the tailing effect of shorter puffs than the 6-s puffs used in this study and to understand the effect of inertial gas flow on filtration behaviour. It is known that the amount of the smoke aerosol produced by the burning coal in an unfiltered cigarette rises approximately exponentially (35). More detailed experimental and modelling work may be needed to identify, at a mechanistic level, the net contribution of the temperature, chemical interactions on the surface and the accumulation of smoke aerosol particles on the total filtration behaviour.
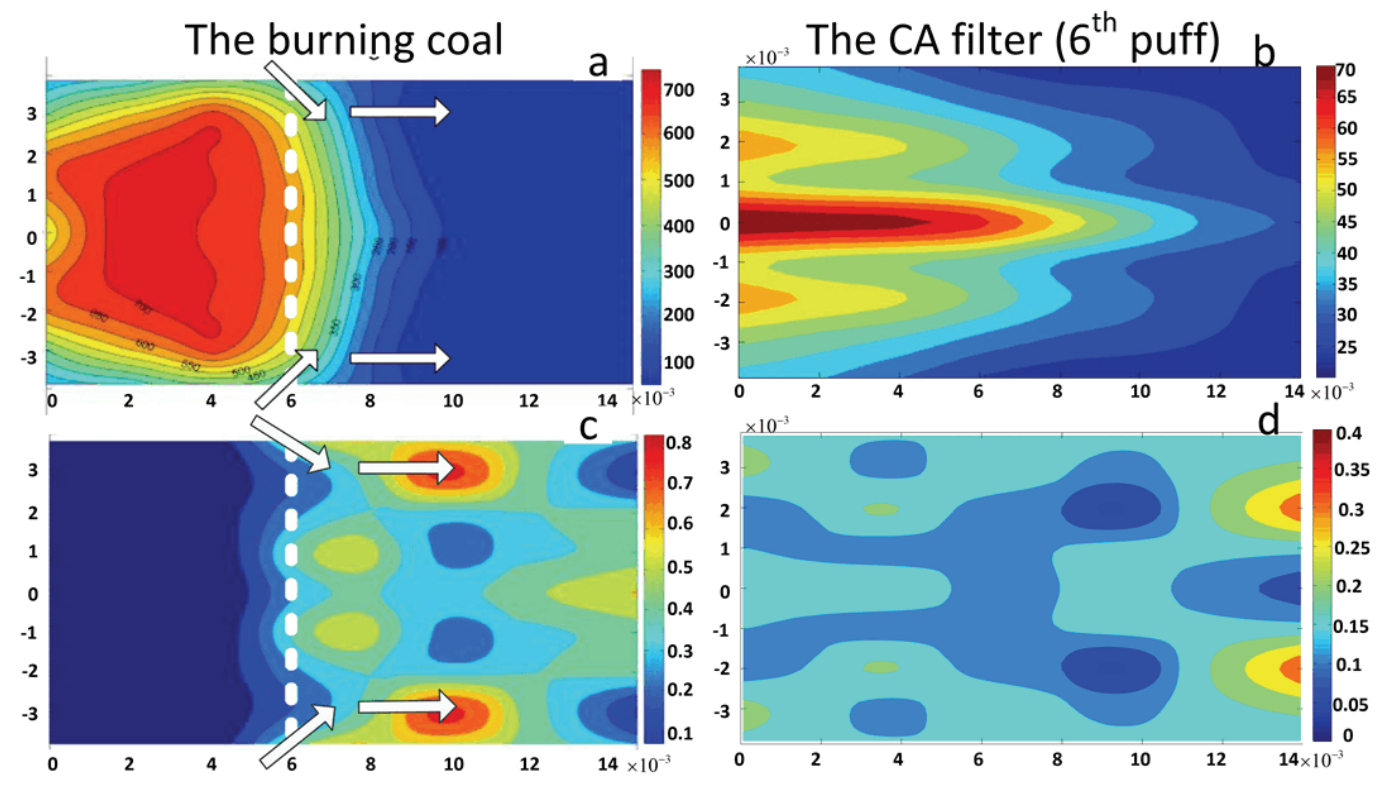

Figure 9. Comparing temperature $\left({ }^{\circ} \mathrm{C}\right)$, and gas velocity $(\mathrm{m} / \mathrm{s})$ distribution of the burning coal (left) from a previous study $(28)$ and that of the cigarette filter (right) in this study. 


\section{CONCLUSIONS}

This paper established an experimental method using pressure and temperature micro-sensors to detect dynamic temperature and pressure responses inside a cellulose acetate filter during cigarette smoking. The combination of the temperature and pressure measurements allowed the flow velocity inside the filter to be calculated based on Darcy's Law. The methodology was applied to a 3R4F cigarette under a $35-\mathrm{mL}$ puff of $6 \mathrm{~s}$ duration rather than the standard 2-s puff duration. This was done to minimize the inertial flow. Under such puffing conditions, the effect of the individual puffs on the gas-phase temperature, pressure and velocity maps within the $3 \mathrm{R} 4 \mathrm{~F}$ cigarette filter was established. The detailed information on pressure and flow velocity distribution provided insights on the filtration behaviour and may provide opportunities to use targeted adsorption and filtration to reduce harmful smoke components.

\section{ACKNOWLEDGEMENTS}

The authors wish to thank Dr Chuan Liu of R\&D Centre of British American Tobacco for useful discussions during the preparation of this manuscript. This work is funded by CNTC's Project.

\section{REFERENCES}

1. Norman, A.: Cigarette Design and Materials; in: Tobacco: Production, Chemistry and Technology, edited by D.L. Davis and M.T. Nielsen, Blackwell Science, Oxford, UK, 1999, pp. 353-387.

2. Fuchs, N.A. and I.B. Stechkina: A Note on the Theory of Fibrous Aerosol Filters; Ann. Occup. Hyg. 6 (1963) 27-30. DOI: 10.1093/annhyg/6.1.27

3. Keith, C.H.: Pressure Drop-Flow Relationships in Cigarette Filter Rods and Tobacco Columns; Beitr. Tabakforsch. Int. 11 (1982) 115-121.

DOI: $10.2478 /$ cttr-2013-0505

4. Keith, C.H.: Physical Mechanisms of Smoke Filtration; Rec. Adv. Tob. Sci 4 (1978) 25-45.

5. Keith, C.H.: Experimental and Theoretical Aspects of Cigarette Smoke Filtration; American Chemical Society Symposium Series 17 (1975) 79-90. eISBN: 9780841202351

6. Keith, C.H. and J.C. Derrick: Cigarette Filter Efficiency as Measured with a Homogeneous Solid Aerosol; Tob. Sci. 9 (1965) 116-120.

7. Overton, J.R.: Filtration of Cigarette Smoke: Relative Contributions of Inertial Impaction, Diffusional Deposition, and Direct Interception; Beitr. Tabakforsch. 7 (1973) 117-120. DOI: $10.2478 / \mathrm{cttr}-2013-0319$

8. Duke, M.G.: Predicting the Efficiency of Cigarette Filters; Filtr. Separat. (1986) 358-366.

9. Morie, G.P., C.H. Sloan, and M.S. Baggett: Parameters Affecting the Selective Filtration of Certain Tobacco Smoke Components; Beitr. Tabakforsch. 8 (1975) 145-149. DOI: 10.2478/cttr-2013-0371
10. Baggett, M.S. and G.P. Morie: Selective Removal of Semivolatile Components of Cigarette Smoke by Various Filters; Beitr. Tabakforsch. 8 (1975) 150-152. DOI: $10.2478 /$ cttr-2013-0372

11. Branton, P.J., K.G. McAdam, D.B. Winter, C. Liu, M.G. Duke, and C.J. Proctor: Reduction of Aldehydes and Hydrogen Cyanide Yields in Mainstream Cigarette Smoke Using an Amine Functionalised Ion Exchange Resin; Chem. Cent. J 5 (2011) 5-15. DOI: $10.1186 / 1752-153 X-5-15$

12. Branton, P.J., K.G. McAdam, M.G. Duke, C. Liu, M. Curle, M. Mola, C.J. Proctor and R. Bradley: Use of Classical Adsorption Theory to Understand the Dynamic Filtration of Volatile Toxicants in Cigarette Smoke by Active Carbons; Adsorpt. Sci. Technol. 29 (2011) 117-138. Available at: http://journals.sagepub. com/doi/pdf/10.1260/0263-6174.29.2.117 (accessed March 2017) DOI: 10.1260/0263-6174.29.2.117

13. Borgerding, M. and H. Klus: Analysis of Complex Mixtures - Cigarette Smoke; Exp. Toxicol. Pathol. 57 (2005) 43-73.

14. Hoffmann, D. and I. Hoffmann: The Changing Cigarette: Chemical Studies and Bioassays; Smoking and Tobacco Control Monograph 13 (2001) 159-192. DOI:10.1093/acprof:oso/9780199566655.003.0006

15. Baker, R.R.: Smoke Chemistry; in: Tobacco: Production, Chemistry and Technology, edited by D.L. Davis and M.T. Nielsen, Blackwell Science, Oxford, UK, 1999, pp. 398-439.

16. Browne, C.L., C.H. Keith, and R.E. Allen: The Effect of Filter Ventilation on the Yield and Composition of Mainstream and Sidestream Smokes; Beitr. Tabakforsch. Int. 10 (1980) 81-90.

DOI: $10.2478 /$ cttr-2013-0473

17. Colard, S., T. Verron, R. Julien, X. Cahours and S.W. Purkis: Relationship between Cigarette Yields and Smoking Time under Different Machine Smoking Regimes; Beitr. Tabakforsch. Int. 26 (2014) 4-18. DOI: $10.2478 /$ cttr-2014-0003

18. Bernstein, D.M.: A Review of the Influence of Particle Size, Puff Volume, and Inhalation Pattern on the Deposition of Cigarette Smoke Particles in the Respiratory Tract; Inhal. Toxicol. 16 (2004) 675-689. DOI: $10.1080 / 08958370490476587$

19. Baker, R.R. and L.S. Lewis: A Review of the Incidence and Consequences of Cigarette Filter Vent Blocking Among Smokers; Beitr. Tabakforsch. Int. 19 (2001) 209-228. DOI: 10.2478/cttr-2013-0709

20. Baker, R.R., M. Dixon, and C.A. Hill: The Influence and Consequences of Filter Vent Blocking Amongst British Smokers; Beitr. Tabakforsch. Int. 18 (1998) 71-83. DOI: $10.2478 /$ cttr-2013-0672

21. Purkis, S.W., C. Mueller, M. Intorp, and H. Seidel: The Influence of Cigarette Designs and Smoking Regimes on Vapour Phase Yields; Beitr. Tabakforsch. Int. 24 (2010) 34-46. DOI: 10.2478/cttr-2013-0879

22. Wen, J.H., W. Du, B. Peng, X.B. Zhang, F.W. Xie, H.M. Liu, and Z. Kejun: Filtration and Retention Characteristics of Smoke Components in Filters; Beitr. Tabakforsch. Int. 26 (2014) 121-131. DOI: $10.2478 /$ cttr-2014-0015

23. Du, W., J.H. Wen, B. Peng, X.B. Zhang, F.W. Xie, 
H.M. Liu, and K.J. Zhong: An Improved Theoretical Model of Cigarette Smoke Filtration across MonoSegment Cellulose Acetate Filters; Beitr. Tabakforsch. Int. 26 (2015) 232-240. DOI: 10.1515/cttr-2015-0011

24. Li, B., L.C. Zhao, C.F. Yu, C. Liu, Y. Jing, H.R. Pang, B. Wang, and K.G. McAdam: Effect of Machine Smoking Intensity and Filter Ventilation Level on Gas-Phase Temperature Distribution Inside a Burning Cigarette; Beitr. Tabakforsch. Int. 26 (2014) 191-203. DOI: $10.1515 / \mathrm{cttr}-2015-0007$

25. Li, B., H.R. Pang, L.C. Zhao, B. Wang, C. Liu, K.G. McAdam, and D.S. Luo: Quantifying Gas-Phase Temperature Inside a Burning Cigarette; Ind. Eng. Chem. Res. 53 (2014) 7810-7820.

DOI: 10.1021/ie5009822

26. MathWorks: Interpolation for 2-D Gridded Data in Meshgrid Format.

Available at: http://www.mathworks.com (accessed March 2017)

27. Baker, R.R.: Gas Velocities inside a Burning Cigarette; Nature 264 (1976) 167-169. DOI: $10.1038 / 264167 \mathrm{~b} 0$

28. Li, B., L.C. Zhao, L. Wang, C. Liu, K.G. McAdam, and B. Wang: Gas-Phase Pressure and Flow Velocity Fields Inside a Burning Cigarette During a Puff; Thermochim. Acta 623 (2016) 22-28. DOI: $10.1016 /$ j.tca.2015.11.006

29. Lee, S., S.K. Lele, and P. Moin: Eddy Shocklets in Decaying Compressible Turbulence; Phys. Fluids 3 (1991) 657-664.

30. International Organization for Standardization (ISO): International Standard ISO 3308:2000. Routine Analytical Cigarette-Smoking Machine - Definition and Standard Conditions; $4^{\text {th }}$ Edition, ISO, Geneva, Switzerland, 2000.
31. Colard, S. and R. Julien: Characterisation of the Draw Resistance Across a Lit Cigarette; Beitr. Tabakforsch. Int. 25 (2013) 586-594. DOI: 10.2478/cttr-2013-0935

32. Gaisser, H.: Fluiddynamik in der Cigarette und deren Einfluß auf den Zugwiderstand; Beitr. Tabakforsch. Int. 16 (1994) 11-46. DOI: 10.2478/cttr-2013-0630

33. University of Kentucky, College of Agriculture, Reference Cigarette Program: The Reference Cigarette; Available at: https://ctrp.uky.edu/resources/pdf/ webdocs/3R4F\%20Preliminary\%20Analysis.pdf (accessed April 2017)

34. Baker, R.R.: Contributions to the Draw Resistance of a Burning Cigarette; Beitr. Tabakforsch. 8 (1975) 124-131. DOI: $10.2478 / \mathrm{cttr}-2013-0367$

35. Watson, C.H., G.M. Polzin, A.M. Calafat, and D.L. Ashley: Determination of Tar, Nicotine, and Carbon Monoxide Yields in the Smoke of Bidi Cigarettes; Nicotine Tob. Res. 5 (2003) 747-753. DOI: $10.1080 / 1462220031000158591$

\section{Corresponding author:}

Bin Li, Ph.D.

Zhengzhou Tobacco Research Institute of CNTC

Zhengzhou 450001

China

E-mail: ztrilibin@163.com 